
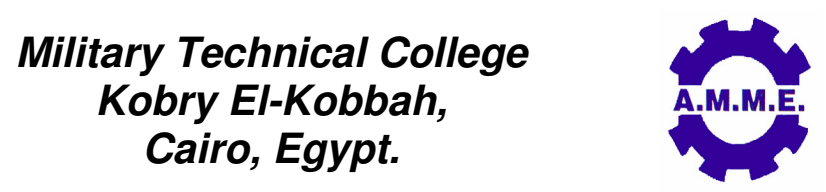
$15^{\text {th }}$ International Conference on Applied Mechanics and Mechanical Engineering.

\title{
EMERGING DEVELOPMENT IN AL-ALLOY RECYCLING FOR NONTRADITIONAL ALUMINUM METAL MATRIX COMPOSITES PROCESSING
}

B. M. Rabeeh *

\begin{abstract}
Growing demands for new emerging materials aimed at introducing nontraditional processes. However, Direct metal oxidation, DIMOX, is applied on Al-alloy, recycling has been prompted to redesign production processes to more cost efficient. Aluminum alloy (scrap) is heated at different temperatures, $950^{\circ} \mathrm{C}, 1000^{\circ} \mathrm{C}$, and $1050^{\circ} \mathrm{C}$ for holding different times $(15$ to 90 minutes) and then poured into metallic mold. The kinetic of formation of hybrid composite is introduced with the effect of alloying elements addition ( $\alpha-\mathrm{Fe}$, and $\mathrm{Si})$. Ceramic alumina phase with intermetallic fibers or whiskers established in a residual aluminum matrix. Functionally graded materials, FGM, is also introduced at prolonged holding time $\left(90 \mathrm{~min}\right.$. at $\left.1050^{\circ} \mathrm{C}\right)$. In addition to Scanning electron microscopy with energy dispersive X-ray spectroscopy EDX is utilized for micro-structural characterization. Besides, 3-point test is applied on another group of samples. The application of DIMOX on recycled Al-alloy with the addition of alloying elements has a dominant effect on composite micro-structural characterization.
\end{abstract}

\section{KEY WORDS}

Composite, FGM, Hybrid, Intermetallic, Micro and macro segregation, DIMOX, Recycling.

\footnotetext{
* Professor, Dept. of Engineering and Materials Science, German University in Cairo, GUC.
} 


\title{
NOMENCLATURES
}

\author{
$\alpha \ldots$ ferrite \\ DIMOX Direct Metal Oxidation \\ EDS Energy Dispersive X-Ray Spectroscopy \\ SEM Scanning Electron Microscopy
}

\section{INTRODUCTION}

For the objective of minimizing cost and maximizing performance, aluminum scrap alloy (automobile pistons scrap) is recycled utilizing direct metal oxidation process, DIMOX. DIMOX is applied at different levels of temperatures, $950^{\circ} \mathrm{C}, 1000^{\circ} \mathrm{C}$, and $1050^{\circ} \mathrm{C}$ and for different holding times ( 15 to 90 minutes) then cast in a metallic mold [1]. No clear evidence of oxidation before $920^{\circ} \mathrm{C}$, while porosity is dominant around $1100^{\circ} \mathrm{C}$ [1-2]. The commencement of alumina as well as intermetallic whiskers established with residual aluminum dominated by DIMOX temperatures [3-5]. Holding time is dominant for alloy segregation as well as the growth of micro constituents [6]. The commencement of $\alpha$ alumina, intermetallic fibers/whiskers, and the segregation, of alloying elements is introduced in a residual bulk aluminum matrix [7-8]. Both composite constituents are controlled for the objective of obtaining metal matrix. Emerging development for composite recycling is introduced through the application of DIMOX for nontraditional composite processing. The addition of alloying elements $\alpha$-Fe or $\mathrm{Si}$ in a powder form $(\sim 5 \mathrm{wt} . \%)$ introduced at different DIMOX temperatures.

The effect of $\alpha$-Fe and Si powder addition resolved with different functions. Addition of $\alpha-$ Fe powder has a powerful effect of nucleating intermetallic fibers as well as alumina fibers homogeneously distributed along residual aluminum. Synergetic effects of $\alpha$-Fe with DIMOX as well as holding time have a dominant effect on the morphology of composite constituents. However, $\alpha-F e$ powder is introduced, fine fibrous structure of Fe established in a residual aluminum matrix. The growth of fibrous structure established by holding time increase. On other side, the addition of Si powder, established with new morphology. The effect of alloying elements addition induces the segregation of alloying elements as well as the introduction if delocalized zone of interests, residual aluminum reinforced with ceramic phase alumina or intermetallic whiskers/fibers as well as ceramic fine grain alumina. The segregation of alloying elements induce delocalized zone of interests induced by Si-addition. More investigation of alloy segregation established by EDX at different DIMOX temperature as well as different holding time. At certain level of holding time, delocalized zone of interest induced functionally-graded-materials, FGM that reveals ceramic alumina with fine grain transitionally gradient to bulk aluminum with intermetallic whiskers. Synergetic effect of alloying elements established for functionally gradient structure.

Scanning electron microscopy and energy dispersive X-ray spectroscopy (EDS) is utilized. In addition, mechanical characterization is introduced through 3-point test. Modulus of rupture is calculated for square cross section sample and compared. Mechanical characterization is also introduced through 3-point testing of metallic mold casted samples of 
10x10x55 mm. Modulus of rupture [MOR] is calculated for different samples. Alloy segregation established for different composite constituents that reveal functionally-gradedmaterials FGM.

\section{EXPERIMENTAL RESULTS AND DISCUSSION}

Chemical composition of aluminum scrap is introduced in Table 1. Microstructural analysis established on first set of samples. Figure 1 presents fracture surface of recycled aluminum DIMOX at $950^{\circ} \mathrm{C}$ for 15 minutes holding time with the commencement of $\alpha$-alumina in a residual aluminum. The commencement of $\alpha$-alumina in residual aluminum at $950^{\circ} \mathrm{C}$ [left], with intermetallic fiber established at $1000^{\circ} \mathrm{C}$ [right]. Figure 2 presents the effect of addition of $\alpha-\mathrm{Fe}$ into recycled aluminum DIMOX at $1000^{\circ} \mathrm{C}$ for 30 minutes [left], and that DIMOX at $1050^{\circ} \mathrm{C}$ for 30 minutes [right]. Temperature of DIMOX induces the growth kinetic of fibrous intermetallic structure. Fracture surface reveals alloying elements segregation as induced by the addition of a-Fe powder and presented in Figure 3. $\alpha$-alumina as well as $\mathrm{Al}$ and $\mathrm{Si}$ segregation is cached and presented in Figure 3 [left], while EDX of intermetallic induced by $\alpha$-Fe addition is presented in Figure 3 [right]. The chemical composition of intermetallic fibers is $47.084 \% \mathrm{Al}, 20.226 \% \mathrm{Si}$, and $32.69 \% \mathrm{Fe}$. On the contrary, the addition of $\mathrm{Si}$ induces the formation of intermetallic whiskers, faceted structure instead of fibers that presented in Figure 4. Alloy segregation at $1000^{\circ} \mathrm{C}$ for $60 \mathrm{~min}$. [left], 1050 for $60 \mathrm{~min}$. [right]. The intermetallic whiskers has nearly close chemical composition of $47.036 \% \mathrm{Al}$, $31.346 \% \mathrm{Si}$, and $21.617 \% \mathrm{Fe}$ at at $1000^{\circ} \mathrm{C}$ for $60 \mathrm{~min}$. [left], and $47.046 \% \mathrm{Al}, 32.438 \% \mathrm{Si}$, and $20.516 \% \mathrm{Fe}$ at $1050^{\circ} \mathrm{C}$ for $60 \mathrm{~min}$. [right]. Si-addition induces not only the segregation of alloying elements for faceted intermetallic structure but also the segregation of alloying elements to functionally graded materials FGM at $1050{ }^{\circ} \mathrm{C}$ for 90 minutes. Fig.5. presents $\mathrm{Si}$ addition that induced FGM with EDX of Al [left], EDX of Si [right]. The distribution of aluminum reveals that alumina is available with fine grain [right] and residual aluminum in intermetallic whiskers at [left]. Figure 6 presents high magnification that reveal FGM with no discrete interface of micro-cracking at the meshing interface at Low mag. [left], and at high mag. [right]. These two different two delocalized zones of alumina and residual aluminum with intermetallic are separately presented in Figure 7 at $1050^{\circ} \mathrm{C}$ for 90 minutes as intermetallic with $\mathrm{Al}$ [left], and alumina fine structure [right].

Figures 8 to 10 present EDX of alumina, intermetallic and residual aluminum respectively. Figure 11 presents 3-point test that illustrate the effect of addition of $\alpha$-Fe on recycled aluminum alloy. Figure 11 [left] present 3-point tests without addition, and Figure 11 [right] present 3-point test with $\alpha$-Fe addition. Table 2 presents the effect of alloying elements addition on modulus of rupture compared to DIMOX samples without addition. The addition of both $\alpha-\mathrm{Fe}$ and $\mathrm{Si}$ induced a clear evidence of alumina phase at DIMOX temperatures in metal matrix composite but with different morphology. A clear difference introduced that resolve intermetallic fibers via steel addition, and FGM via Si addition. In addition the effect of alloying elements segregation introduced with EDX. The formation of new phase in residual aluminum due to the addition of $\alpha-\mathrm{Fe}$ or Si induced an increase of MOR [Table 2].

Table 1. Chemical composition of as received used raw materials

\begin{tabular}{|c|c|c|c|c|c|c|c|c|c|c|c|c|}
\hline Elements & $\mathrm{Si}$ & $\mathrm{Mg}$ & $\mathrm{Fe}$ & $\mathrm{Ni}$ & $\mathrm{Cu}$ & $\mathrm{Mn}$ & Ti & $\mathrm{Zr}$ & $\mathrm{V}$ & $\mathrm{Zn}$ & $\mathrm{Sr}$ & $\mathrm{Al}$ \\
\hline From & 11.0 & 0.5 & 0.0 & 0.05 & 0.06 & 0.0 & 0.05 & 0.12 & 0.05 & 0.05 & 0.001 & \multirow{2}{*}{$\begin{array}{r}\text { Balance } \\
\text { Wt } \%\end{array}$} \\
\hline To & 14.0 & 1.5 & 0.8 & 0.9 & 0.8 & 1.0 & 1.2 & 1.2 & 1.2 & 0.9 & 0.1 & \\
\hline
\end{tabular}




\section{CONCLUSIONS}

The introduction of non-traditional process for the recycling of aluminum scrap is established via DIMOX and alloying element addition. DIMOX has dominant effects on the formation of alumina ceramic phase as well as intermetallic fibers/whiskers within bulk matrix in metal matrix composite. The control of both composite constituents [reinforcements and matrix] is introduced via the addition of alloying elements. $\alpha$-Fe has the effect of formation of intermetallic fibers within bulk aluminum matrix composite. Si has the effect of introducing intermetallic whiskers within functionally-graded-materials, FGM.
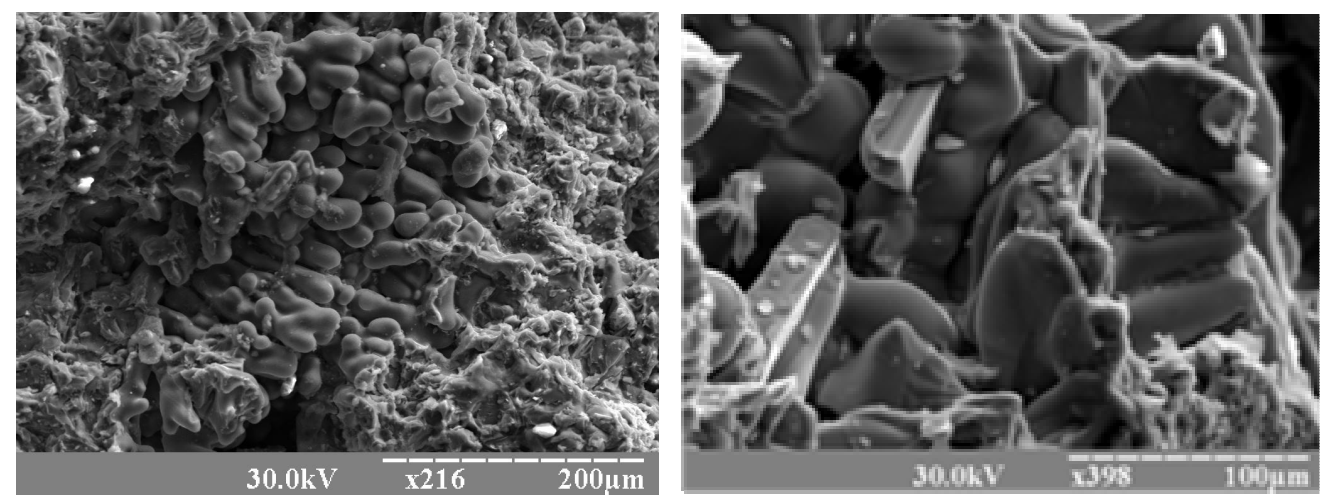

Fig. 1. The commencement of a-alumina in residual aluminum at $950^{\circ} \mathrm{C}[\mathrm{left}]$, with intermetallic at $1000^{\circ} \mathrm{C}$ [right].
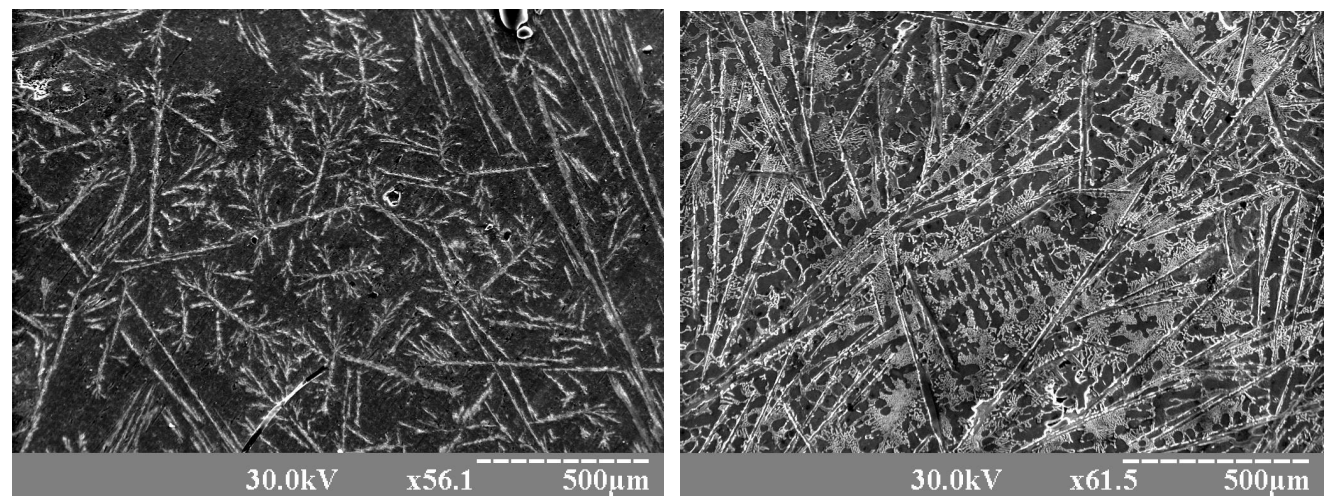

Fig. 2. $\alpha$-Fe induced Intermetallic fibers in residual $\mathrm{Al}$ for $30 \mathrm{~min}$. at $1000 \mathrm{oC}$ [left] and at $1050 \mathrm{oC}$ [right] 

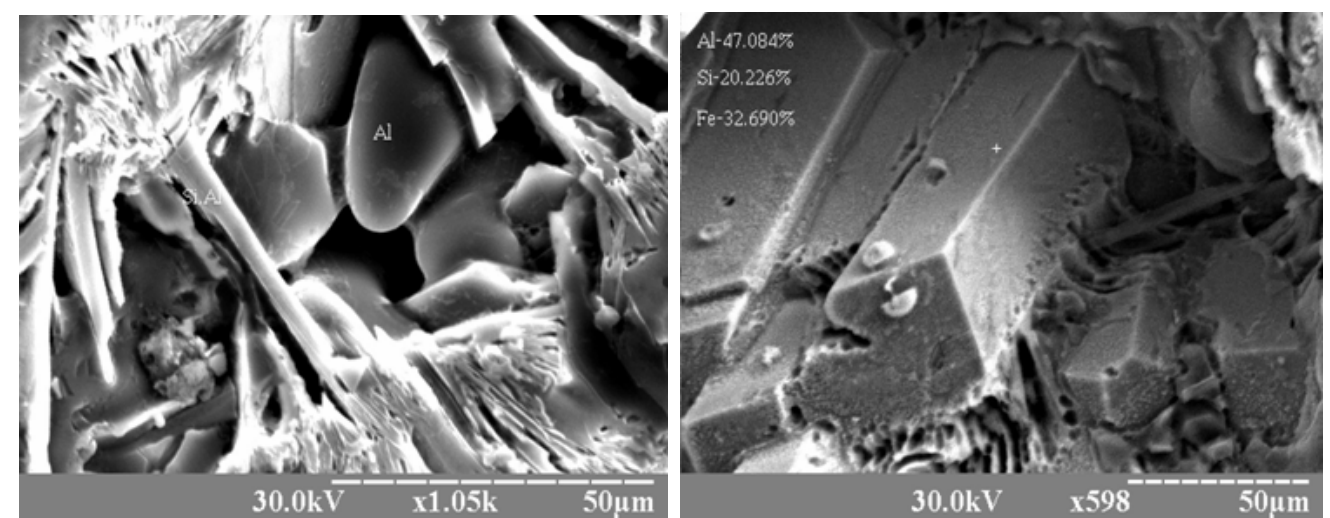

Fig. 3. Si induced $\alpha$-alumina and intermetallic in residual aluminium. Alloy segregation branched [left], intermetallic [right].
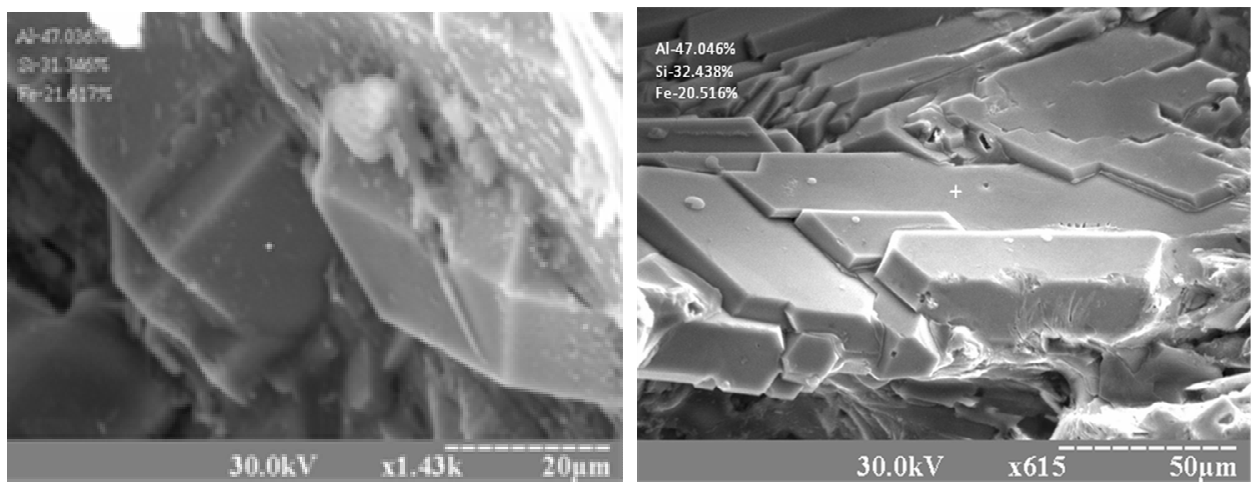

Fig. 4. Si-addition induced alloy segregation at $1000^{\circ} \mathrm{C}$ for $60 \mathrm{~min}$. [left], $1050^{\circ} \mathrm{C}$ for $60 \mathrm{~min}$. [right].
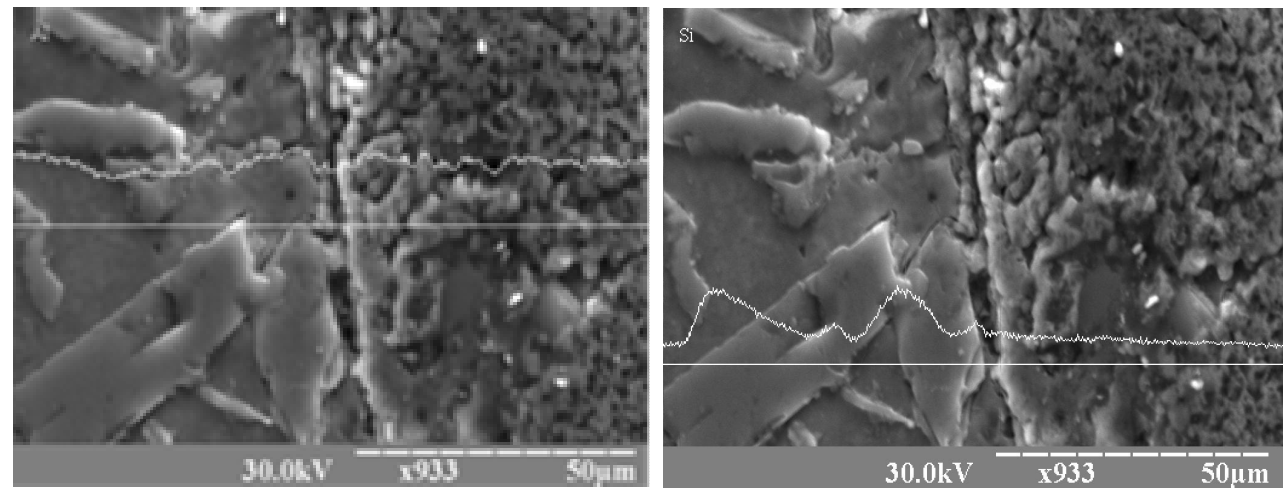

Fig.5. Si addition induced $\mathrm{FGM}$ at $1050^{\circ} \mathrm{C}$ and $90 \mathrm{~min}$ holding time. EDX of Al distribution [left], and EDX of Si distribution[right]. 

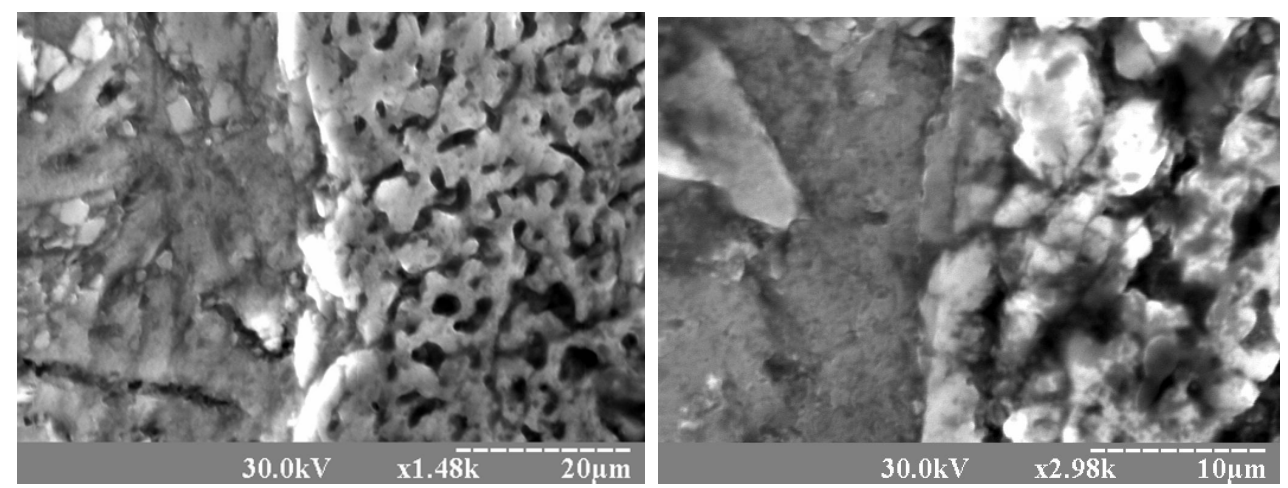

Fig.6. Si addition induced $\mathrm{FGM}$ at $1050^{\circ} \mathrm{C}$ and $90 \mathrm{~min}$. holding time with no discrete interface. Low mag. [left], high mag. [right].
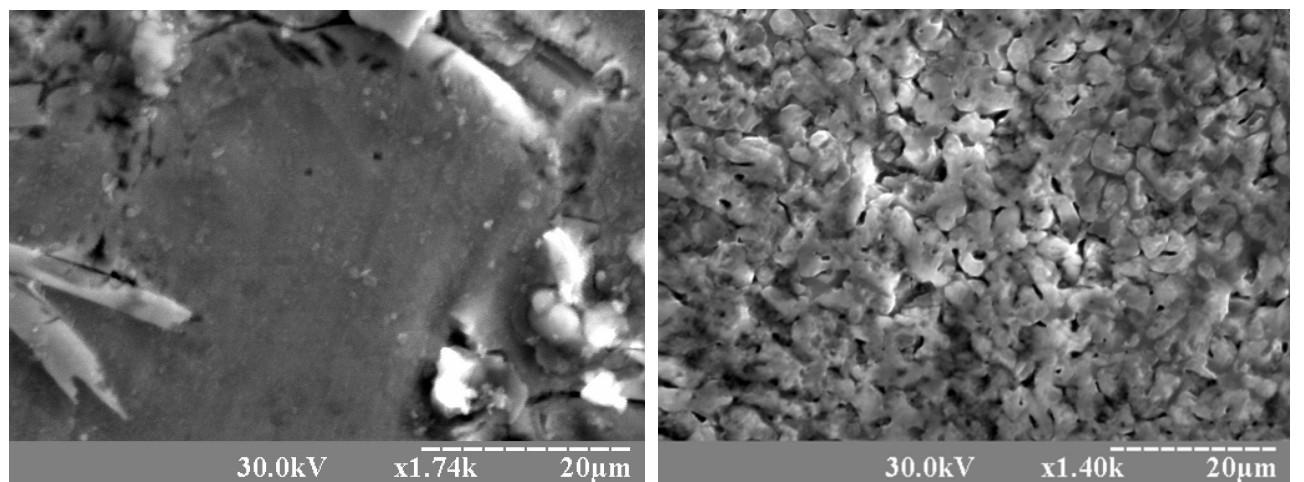

Fig. 7. Si addition induced $\mathrm{FGM}$ at $1050^{\circ} \mathrm{C}$ and $90 \mathrm{~min}$ holding time. Intermetallic with residual $\mathrm{Al}$ [left], bulk alumina [right].
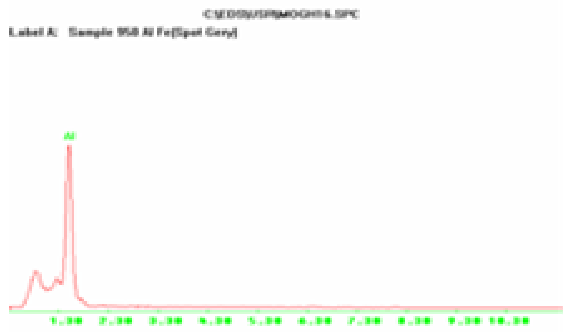

Fig. 8: EDS resolve alumina [gray spot].

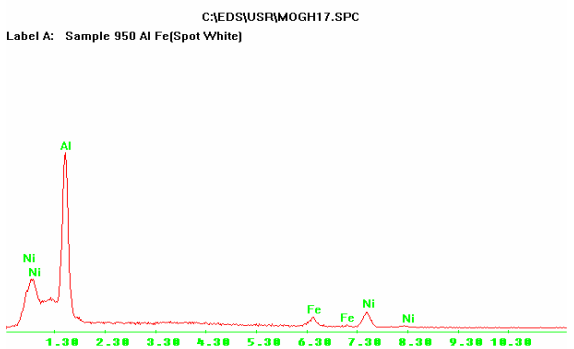

Fig.9. EDS resolve intermetallic fiber 

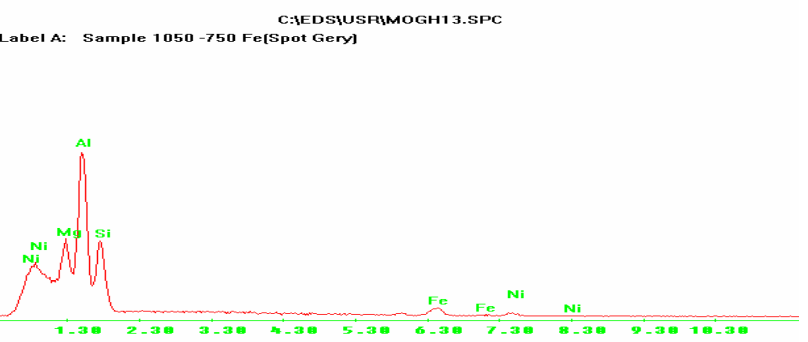

Fig.10. EDS resolve residual aluminium.
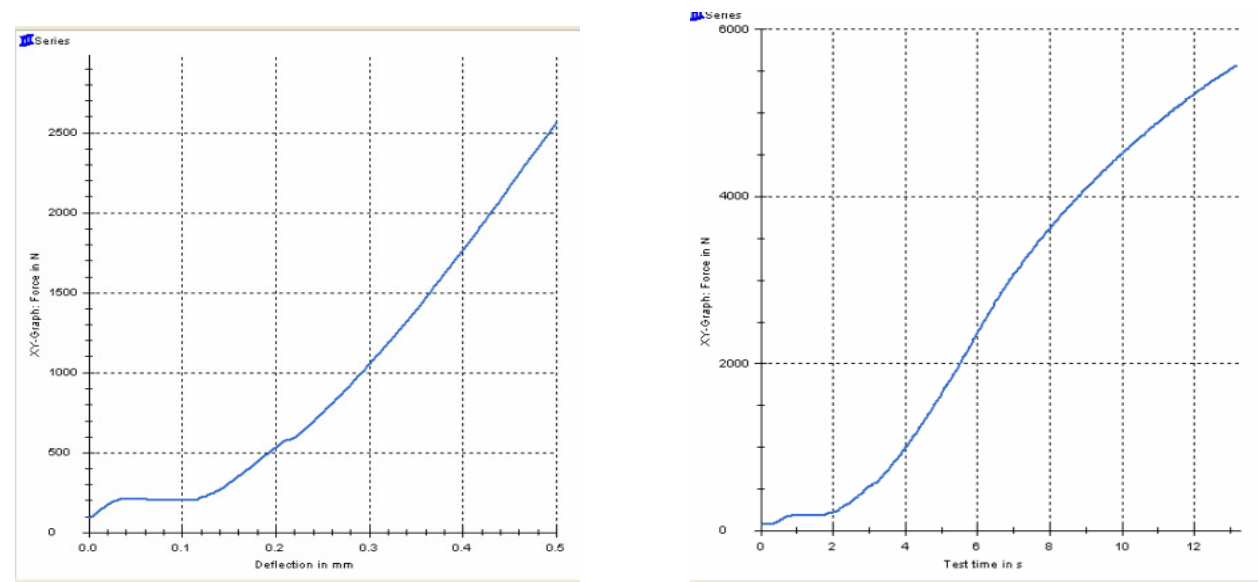

Fig.11. 3-point test illustrate addition of $\alpha$-Fe. Without addition [left], with addition [right].

Table 2: Modulus Of Rupture Resolves The Effect Of Alloying Elements Addition.

\begin{tabular}{|c|c|c|c|}
\hline Sample Classification & \multicolumn{3}{|c|}{ DIMOX } \\
\cline { 2 - 4 } $\mathrm{A}$ alloy scrap & Force [N] & Deflection [mm] & MOR [MPa] \\
\hline at $950^{\circ} \mathrm{C}$ without & 2592 & 0.51 & 194.4 \\
\hline at $1000^{\circ} \mathrm{C}$ without & 2683 & 0.66 & 201.225 \\
\hline at $1050^{\circ} \mathrm{C}$ without & 2900 & 0.53 & 377.5 \\
\hline at $1000^{\circ} \mathrm{C}$ with $\alpha-F e$ & 4963 & 1.00 & 398.55 \\
\hline at $1050^{\circ} \mathrm{C}$ with $\alpha-F e$ & 5314 & 0.60 & 387.675 \\
\hline at $1050^{\circ} \mathrm{C}$ with $\mathrm{Si}$ & 5169 & 0.63 & \\
\hline
\end{tabular}

The effect of $\alpha-\mathrm{Fe}$ and Si powder resolved with different composite functions. Addition of $\alpha$-Fe powder has a powerful effect of nucleating intermetallic fibers as well as alumina fibers homogeneously distributed along residual aluminum. Synergetic effects of $\alpha$-Fe with DIMOX have a dominant effect on the morphology of composite constituents. Clear intermetallic fibers as well as alumina fibers are introduced as commenced at $950^{\circ} \mathrm{C}$ to $1050^{\circ} \mathrm{C}$ with scanning electron microscopy. However, the addition of $\alpha$-Fe introduced a new functional hybrid material, aluminum alloy reinforced with ceramic alumina as well as intermetallic fibers, in residual aluminum. Addition of $\mathrm{Si}$ induces faceted structures with alumina phase and bulk residual aluminum. Moreover, it induces FGM with delocalized alumina and residual aluminum composite. Functionally-graded-materials, FGM induced by 
the addition of Si with the synergetic effect alloying elements that dominates delocalized zone of interests.

The addition of alloying elements with the nontraditional processes [DIMOX] clearly dominates two functional materials. The first established with $\alpha$-Fe addition leading to the third generation metal matrix composite with both alumina and intermetallic fibers reinforcements. The second dominated by the addition of Si that induced whiskers with new FGM. This may lead to more mechanical properties as well as high performance materials. There is some evidence of mechanical enhancement as increase of modulus of rupture for different samples. Synergetic effects of alloying elements as well as DIMOX parametric induced different intermetallic kinetics as well as delocalized zone of interests. DIMOX processing induced engineering of new materials with different functions. A hybrid composite of aluminum metal matrix reinforced with alumina particulate as well as intermetallic whiskers and/or fibers are introduced. In addition delocalized zone of interests are also introduced with a new functionally- graded-Materials [FGM].

\section{REFERENCES}

[1] B. M. Rabeeh, A.M.Elmahallawy, S. H. Haddad, and M. A. Ibrahim "Development and Processing of a functionally Gradient Ceramic/Metal Materials ", Proceeding of the $9^{\text {th }}$ Applied Mechanics and Mechanical Engineering Conference, AMME Conf. 16-18 May, 2000, Cairo, Egypt.

[2] C.D. Marioara, S.J. Andersen, J. Jansen, H.W. Zandbergen, "The influence of temperature and storage time at RT on nucleation of the $\beta$ phase in a $6082 \mathrm{Al}-\mathrm{Mg}-\mathrm{Si}$ alloy", Acta Mater 51 (2003) 789-796.

[3] N.C.W. Kuijpers, W.H. Kool, P.T.G. Koenis, K.E. Nilsen, I.Todd, S. van der Zwaag, "Assessment of diffrent techniques for quantification of $\alpha-\mathrm{Al}(\mathrm{FeMn}) \mathrm{Si}$ and $\beta-\mathrm{AlFeSi}$ intermetallics in A 6xxx alloys", Materials Characterization 49 (2003) 409-420.

[4] G. Mrówka-Nowotnik, J. Sieniawski, "Influence of heat treatment on the micrustructure and mechanical properties of 6005 and 6082 aluminium alloys", Journal of Materials Processing Technology 162-163 (2005) 367-372.

[5] L.F. Mondolfo, “Aluminium Alloys, Structure and Properties", Butterworths, LondonBoston, 1976.

[6] M. Warmuzek,K. Rabczak, J. Sieniawski, "The course of the peritectic transformation in the Al-rich Al-Fe-Mn-Si alloys", Journal of Materials Processing Technology 162163 (2005) 422-428.

[7] M. Warmuzek, J. Sieniawski, K. Wicher, G. Mrówka- Nowotnik, "The study of distribution of the transition metals and $\mathrm{Si}$ during primary precipitation of the intermetallic phases in Al-Mn-Si alloys", Journal of Materials Processing Technology

[8] $\quad 175$ 1-3 (2006) 421-426.

L.A. Dobrzanski, W. Borek, R. Maniara, "Influence of the crystallization condition on $\mathrm{Al}-\mathrm{Si}-\mathrm{Cu}$ casting alloys structure", Journal of of Achievements in Materials and

[9] Manufacturing Engineering 18, 1-2 (2006) 211-214.

G. Mrówka-Nowotnik, J. Sieniawski, M. Wierzbińska, "Analysis of intermetallic particles in AlSi1MgMn aluminium alloy", Journal of of Achievements in Materials and Manufacturing Engineering, Volume 20, issues 1-2, January-February 2007.155158. 